\title{
COMMENTARY
}

\section{Unrevealing culture-negative severe sepsis}

\author{
Nicolas de Prost, Keyvan Razazi and Christian Brun-Buisson* \\ See related research by Phua et al., http://ccforum.com/content/17/5/R202
}

\begin{abstract}
Sepsis involves a wide array of sources and microorganisms, only a fraction of which are microbiologically documented. Culture-negative sepsis poses special diagnostic challenges to both clinicians and microbiologists and further questions the validity of sepsis definitions.
\end{abstract}

According to the 2012 Surviving Sepsis Campaign, sepsis is a 'systemic, deleterious host response to infection', characterized as 'suspected or documented', which can lead to severe sepsis as defined by an 'acute organ dysfunction secondary to infection' [1]. Central to this definition is the presence of an infectious process, which differentiates sepsis from other causes of severe inflammation. However, only about 40 to $60 \%$ of patients with severe sepsis or shock have a microbiologically documented infection. In a substantial proportion of patients, sepsis will remain only clinically suspected, raising the possibility of a non-infectious cause (that is, of severe systemic inflammatory response syndrome).

In this issue of Critical Care, Phua and colleagues reported on a large prospective cohort study of patients $(n=1,001)$ presenting with severe sepsis on ICU admission and compared the characteristics and outcomes of culture-negative versus culture-positive episodes [2]. Their main findings were that culture-negative sepsis occurred in $41.5 \%$ of the cohort, was associated with female gender, less comorbidities or organ failures, and more lung infection $(74.5 \%$ vs. $59.9 \%)$ than their counterparts, and included lower serum procalcitonin levels and ICU mortality; however, identification of a pathogen was not independently associated with mortality in adjusted analyses.

Sepsis is a highly heterogeneous syndrome, affecting patients with various underlying conditions, and

\footnotetext{
* Correspondence: christian.brun-buisson@hmn.aphp.fr

Service de Réanimation Médicale, Hôpital Henri Mondor, 51 Avenue du Maréchal de Lattre de Tassigny, 94010, Créteil, Cedex, France
}

involving an array of infectious sources and microorganisms. Although the characteristics of infection were retained in attempts to better characterize sepsis through the PIRO (predisposition, infection, response and organ failure) concept [3], data are conflicting regarding their impact on outcome of patients $[4,5]$. The observations by Phua and colleagues [2] tend to confirm earlier epidemiological studies showing that patients with or without microbiological documentation were at similarly high risk of death [6-8]. Despite this apparent lack of influence on outcome of patients, nondocumented sepsis challenges both our understanding of sepsis and management strategy. Indeed, the highest possible rate of documentation is desirable, as this would allow for a more targeted therapy in many patients, possibly avoiding unnecessary prolonged administration of broad-spectrum antibiotics [1].

Why should patients presenting with a clinical syndrome of severe sepsis have nondocumented infection? Firstly, patients may have received antibiotics prior to the onset of organ dysfunction, thus obscuring conventional cultures. For example, patients with communityacquired respiratory tract infection often receive antibiotics before ICU admission, and not surprisingly Phua and colleagues report that respiratory tract infection was associated with culture-negative sepsis [2]. They did not, however, record information on prior antibiotic treatment, and this hypothesis cannot be substantiated.

Secondly, the diagnostic workup may be insufficient or incomplete, which does seem to apply to the current study because patients with positive or negative cultures appeared to have a similar number of samples taken [2].

A third possible explanation is sepsis caused by unusual organisms that are difficult to identify in routine practice. Conventional microbiological methods frequently fail to indentify a microorganism due to various reasons related to technical issues or intrinsic to the microorganism. Promising studies using PCR methods showed that microbial DNA could be rapidly detected in blood of septic patients [9], and could detect potentially 
significant bacteria and fungi not retrieved from blood culture $[9,10]$. In a recent meta-analysis, the overall sensitivity and specificity for such methods to detect bacterial or fungal DNA were 0.75 and 0.92 [11]. However, even in patients with severe sepsis, the rate of positive blood PCRs was only $34.7 \%$ [9]. Patients with culture-negative sepsis described by Phua and colleagues [2] having lower serum procalcitonin levels than others also suggests that at least some of them may have had severe viral infections. Indeed, a recent study showed that approximately one-third of ICU patients with severe pneumonia had viruses found by PCR assays on nasopharyngeal swabs or bronchoalveolar lavage fluid [12].

A fourth explanation is that some patients having culture-negative sepsis might actually have a noninfectious cause for the clinical syndrome. Indeed, Phua and colleagues report a few $(n=18)$ patients with culturenegative sepsis having an unknown source of infection [2], raising the question of whether these patients with severe systemic inflammatory response syndrome truly had an underlying infection. Indeed, numerous differential diagnoses of severe sepsis have been previously described, including various tissue injuries (for example, surgery/trauma, ischemia, and so forth), metabolic disorders (for example, thyroid storm), adverse effects of drugs, inflammatory diseases (for example, systemic lupus erythematosus, DRESS syndrome, and so forth), malignancies and subarachnoid hemorrhage $[13,14]$. One could reasonably hypothesize that some of these mimickers of sepsis accounted for some of the culture-negative severe sepsis in the study from Phua and colleagues [2].

Although the study by Phua and colleagues leaves several questions unanswered, it highlights the persisting gaps in our current understanding of sepsis and provides insightful information on the clinical features of nondocumented sepsis [2]. In the future, clinicians should strive to formalize strategies for managing such patients, probably combining clinical findings, imaging, and conventional bacterial cultures, but also the use of biomarkers and perhaps multiplex PCR-based assays to enhance our diagnostic ability.

\section{Abbreviation}

PCR: Polymerase chain reaction.

\section{Competing interests}

$\mathrm{NdP}$ and KR declare that they having no competing interests. CB-B was an investigator in a study on the Septifast ${ }^{\circledR}$ test in septic patients, sponsored by Roche-Diagnostics [10].

\section{Published: 26 September 2013}

\section{References}

1. Dellinger RP, Levy MM, Rhodes A, Annane D, Gerlach H, Opal SM, Sevransky JE, Sprung CL, Douglas IS, Jaeschke R, Osborn TM, Nunnally ME, Townsend SR, Reinhart K, Kleinpell RM, Angus DC, Deutschman CS, Machado FR, Rubenfeld GD, Webb SA, Beale RJ, Vincent JL, Moreno R: Surviving Sepsis
Campaign Guidelines Committee including the Pediatric Subgroup: Surviving sepsis campaign: international guidelines for management of severe sepsis and septic shock: 2012. Crit Care Med 2013, 41:580-637.

2. Phua J, Ngerng WJ, See KC, Tay CK, Kiong T, Lim HF, Chew MY, Yip HS, Tan A, Khalizah HJ, Capistrano R, Lee KH, Mukhopadhyay A: Characteristics and outcomes of culture-negative versus culture-positive severe sepsis. Crit Care 2013, 17:R202.

3. Rubulotta F, Marshall JC, Ramsay G, Nelson D, Levy M, Williams M: Predisposition, insult/infection, response, and organ dysfunction: a new model for staging severe sepsis. Crit Care Med 2009, 37:1329-1335.

4. Cohen J, Cristofaro P, Carlet J, Opal S: New method of classifying infections in critically ill patients. Crit Care Med 2004, 32:1510-1526.

5. Zahar JR, Timsit JF, Garrouste-Orgeas M, Francais A, Vesin A, DescorpsDeclere A, Dubois Y, Souweine B, Haouache H, Goldgran-Toledano D, Allaouchiche B, Azoulay E, Adrie C: Outcomes in severe sepsis and patients with septic shock: pathogen species and infection sites are not associated with mortality. Crit Care Med 2011, 39:1886-1895.

6. Brun-Buisson C, Doyon F, Carlet J, Dellamonica P, Gouin F, Lepoutre A, Mercier JC, Offenstadt G, Regnier B: Incidence, risk factors, and outcome of severe sepsis and septic shock in adults, A multicenter prospective study in intensive care units. French ICU Group for Severe Sepsis. JAMA 1995, 274:968-974.

7. Rangel-Frausto MS, Pittet D, Costigan M, Hwang T, Davis CS, Wenzel RP: The natural history of the systemic inflammatory response syndrome (SIRS), A prospective study. JAMA 1995, 273:117-123.

8. Vincent JL, Sakr Y, Sprung CL, Ranieri VM, Reinhart K, Gerlach H, Moreno R, Carlet J, Le Gall JR, Payen D: Sepsis in European intensive care units: results of the SOAP study. Crit Care Med 2006, 34:344-353.

9. Bloos F, Sachse S, Kortgen A, Pletz MW, Lehmann M, Straube E, Riedemann NC, Reinhart K, Bauer M: Evaluation of a polymerase chain reaction assay for pathogen detection in septic patients under routine condition: an observational study. PLOS One 2012, 7:e46003.

10. Bloos F, Hinder F, Becker K, Sachse S, Mekontso Dessap A, Straube E, Cattoir $V$, Brun-Buisson C, Reinhart K, Peters G, Bauer M: A multicenter trial to compare blood culture with polymerase chain reaction in severe human sepsis. Intensive Care Med 2010, 36:241-247.

11. Chang SS, Hsieh WH, Liu TS, Lee SH, Wang CH, Chou HC, Yeo YH, Tseng CP, Lee CC: Multiplex PCR system for rapid detection of pathogens in patients with presumed sepsis - a systemic review and meta-analysis. PLoS One 2013, 8:e62323.

12. Choi SH, Hong SB, Ko GB, Lee Y, Park HJ, Park SY, Moon SM, Cho OH, Park KH, Chong YP, Kim SH, Huh JW, Sung H, Do KH, Lee SO, Kim MN, Jeong JY, $\operatorname{Lim} \mathrm{CM}, \mathrm{Kim}$ YS, Woo JH, Koh Y: Viral infection in patients with severe pneumonia requiring intensive care unit admission. Am J Respir Crit Care Med 2012, 186:325-332.

13. Cohen J, Brun-Buisson C, Torres A, Jorgensen J: Diagnosis of infection in sepsis: an evidence-based review. Crit Care Med 2004, 32:S466-\$494.

14. Vincent $J$ L, Opal SM, Marshall JC, Tracey KJ: Sepsis definitions: time for change. Lancet 2013, 381:774-775.

doi:10.1186/1364-8535-17-1001

Cite this article as: de Prost et al.: Unrevealing culture-negative severe sepsis. Critical Care 2013 17:1001. 